\title{
Association between collagen type XI $\alpha 1$ gene polymorphisms and papillary thyroid cancer in a Korean population
}

\author{
HAE JEONG PARK ${ }^{1}$, BONG-KEUN CHOE ${ }^{1}$, SU KANG KIM ${ }^{1}$, HYUN-KYUNG PARK ${ }^{1}$, JONG WOO KIM ${ }^{1}$, \\ JOO-HO CHUNG ${ }^{1}$, IL KI HONG ${ }^{2}$, DAE HAN CHUNG ${ }^{3}$ and KEE HWAN KWON ${ }^{3}$ \\ ${ }^{1}$ Kohwang Medical Research Institute; Departments of ${ }^{2}$ Nuclear Medicine, and ${ }^{3}$ Otolaryngology - Head and Neck Surgery, \\ School of Medicine, Kyung Hee University, Seoul, Republic of Korea
}

Received June 7, 2011; Accepted July 12, 2011

DOI: $10.3892 /$ etm.2011.318

\begin{abstract}
Collagen type XI $\alpha 1$ (COL11A1) gene overexpression has been implicated as a candidate marker of various types of cancers. In this study, we investigated whether coding region single nucleotide polymorphisms (cSNPs) of the COL11A1 gene are associated with papillary thyroid cancer (PTC) in a Korean population. Four cSNPs [rs12731843 (Lys276Asn), rs3753841 (Pro1335Leu), rs1763347 (Gly1516Gly) and rs2229783 (Ile1602Ile)] were genotyped using direct sequencing in 98 PTC patients and 366 control subjects. Logistic regression analysis for each cSNP revealed an association between rs1763347 and PTC in a dominant model [CT/TT vs. CC, $\mathrm{p}=0.0042$, odds ratio $(\mathrm{OR})=0.50,95 \%$ confidential interval (CI) 0.31-0.81]. Analysis of allelic frequency showed that the $\mathrm{T}$ alleles of rs1763347 and rs2229783 were significantly associated with reduced risk of PTC $(\mathrm{p}=0.010$, $\mathrm{OR}=0.61,95 \%$ CI $0.42-0.89$ in $\mathrm{rs} 1763347 ; \mathrm{p}=0.007, \mathrm{OR}=0.62$, $95 \%$ CI $0.44-0.88$ in rs2229783). Additionally, in the analysis of haplotype, the $\mathrm{CC}$ haplotype consisting of rs1763347 and rs2229783 was associated with PTC in codominant $(\mathrm{p}=0.011$, $\mathrm{OR}=1.56,95 \%$ CI 1.11-2.21) and recessive models $(\mathrm{p}=0.020$, $\mathrm{OR}=1.70,95 \%$ CI 1.09-2.66). The TT haplotype was also associated with PTC in a codominant model $(\mathrm{p}=0.006, \mathrm{OR}=0.58$, 95\% CI 0.39-0.88). The frequency of the CC haplotype was higher in the PTC patients (0.71) compared to the control subjects $(0.61)$, whereas the frequency of the TT haplotype was lower in the PTC patients $(0.20$ and 0.30 in PTC patients and control subjects, respectively). The results suggest that the COL11A1 gene may be associated with PTC and, in particular, that the T allele of rs1763347 and rs2229783 may contribute to a reduced risk of $\mathrm{PTC}$.
\end{abstract}

Correspondence to: Dr Kee Hwan Kwon, Department of Otolaryngology - Head and Neck Surgery, Kyung Hee University Hospital at Gangdong, 149 Sangil-dong, Gangdong-gu, Seoul 134-727, Republic of Korea

E-mail: hjpark17@gmail.com

Key words: collagen type XI $\alpha 1$, papillary thyroid cancer, single nucleotide polymorphism

\section{Introduction}

Thyroid cancer is the most common endocrine malignancy, accounting for approximately $1 \%$ of all cancers. It is the most rapidly increasing cancer among women and the second most rapidly increasing cancer among men. Histologically, thyroid cancer is classified as papillary thyroid cancer (PTC), follicular thyroid cancer, medullary thyroid cancer and undifferentiated or anaplastic thyroid cancer. Among them, PTC is the most common type and accounts for $85-90 \%$ of all thyroid malignancies $(1,2)$.

Psammoma bodies (PBs), very fine calcifications, are a well-known characteristic of PTC and have diagnostic value $(3,4)$. Although the molecular mechanisms of calcification in these non-osseous tissues are poorly characterized, collagen production by the tumor cells plays an important role in the formation of PBs in PTC, ovarian cancer and meningioma (5-7). Indeed, Tsuchida et al (7) reported that round bodies with concentric laminations that were frequently detected in meningiomas were composed mainly of collagen fibers that emerged from the surrounding tumor cells, suggesting that they could be precursors of PBs.

Collagen type XI $\alpha 1$ (COL11A1) is a minor fibril component of cartilage (8). COL11A is expressed mainly in articular cartilage and controls collagen type II $(9,10)$. It functions in skeletal morphogenesis, fibrillogenesis, chondrocyte maturation and bone mineralization $(11,12)$. In addition, COL11A1 was found to be expressed at a low level in a wide variety of normal adult human tissues, including lung tissue, with the highest expression detected in the parotid gland (13). Little is known about the function of COL11A1 aside from its demonstrated importance in regulating the assembly, organization and development of cartilage. However, importantly, previous studies have found overexpression of the COL11A1 gene in various types of cancers, such as non-small cell lung (NSCLC), ovarian and oral cavity and colorectal cancers (13-16). In particular, overexpression of the COL11A1 gene was found to be correlated with invasion and metastasis of these cancers (13-16). In addition, the association of COL11A1 gene polymorphisms with esophageal squamous cell carcinoma through genome-wide analysis of chromosomal alterations has been reported (17). These studies implicated the COL11A1 gene as a candidate marker of these cancers. 
For PTC, several risk factors, such as ionizing radiation and nodular disease of the thyroid, have been established. Genetic influence is also an established risk factor for PTC (18). The familial risk for PTC is 3 and 6 when a parent and a sibling are diagnosed with thyroid cancers, respectively (19). In addition, recent studies have implicated variants on $1 \mathrm{p} 12$, $8 \mathrm{q} 24,9 \mathrm{q} 22.33$ and in the pre-miR146a at 5q33 in the disease (20-23). However, information concerning the possible variants that affect the risk of PTC is limited. Given the important role of collagen in the formation of PBs and the involvement of COL11A1 in various types of cancers, we speculated that COL11A1 may play a role as a candidate gene having an association with PTC. In this study, we investigated whether COL11A1 gene polymorphisms are associated with susceptibility to PTC in a Korean population.

\section{Materials and methods}

Subjects. Ninety-eight PTC patients [mean age \pm standard deviation (SD) 52.8 \pm 12.2 years; male/female 29/69] and

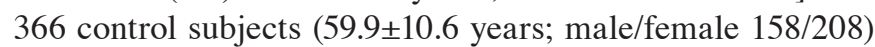
were enrolled in this study. PTC diagnoses and the presence of cervical regional lymph node metastasis were confirmed by pathological examination. The specimens that were diagnosed as follicular variants, diffuse sclerosing and tall cell variants were excluded. None of the controls were diagnosed with cancer or thyroid disease at the time of enrollment. All PTC patients and control subjects were recruited at the Kyung Hee Medical Center, Seoul, Korea, and were of Korean background. Written informed consent was obtained from each subject. The study was approved by the Ethics Review Committee of the Medical Research Institute, Kyung Hee University Medical Center, Seoul, Korea.

Patient subgroups. To determine the nature of the relationship between COL11A1 gene polymorphisms and the clinicopathological characteristics of PTC, the patients were divided into subgroups according to the size of the cancers $(<1$ and $\geq 1 \mathrm{~cm})$, the number of cancers (unifocality and multifocality) and the location of the cancers (one lobe and both lobes). In addition, the PTC patients were also subgrouped into extrathyroidal invasion (+) and (-) groups based on pathological findings. Finally, the PTC patients were further subgrouped into lymph node metastasis (+) and (-) groups to evaluate the contribution of COL11A1 gene polymorphisms to cancer metastasis. Demographic characteristics of the PTC patients are summarized in Table I; small differences in subgroup numbers were caused by loss of certain clinical data.

SNP selection and genotyping. Coding region single nucleotide polymorphisms (cSNPs) for the COL11A1 gene were selected from the SNP database (dbSNP; www.ncbi.nlm.nih.gov/SNP, dbSNP BUILD 129) of the National Center of Biotechnology Information. The cSNPs without genotype frequency data and with a heterozygosity $\leq 0.05$ or a minor allele frequency $\leq 0.05$ in Han Chinese and Japanese populations were excluded. The cSNPs with various genotypes $>3$ were also excluded. Finally, four cSNPs were selected from COL11A1: rs12731843 (Lys276Asn), rs3753841 (Pro1335Leu), rs1763347 (Gly1516Gly) and rs2229783 (Ile1602Ile). DNA was isolated from a periph-
Table I. Clinical characteristics of the study population.

\begin{tabular}{lcc}
\hline & $\begin{array}{c}\text { PTC } \\
(\mathrm{n}=98)\end{array}$ & $\begin{array}{c}\text { Control } \\
(\mathrm{n}=366)\end{array}$ \\
\hline Age (years) & & \\
Mean \pm SD & $52.8 \pm 12.2$ & $59.9 \pm 10.6$ \\
Gender (n) & & \\
Male/female & $29 / 69$ & $158 / 208$ \\
Cancer size (n) & & \\
$<1$ cm & 49 & \\
$\geq 1$ cm & 47 & \\
No. of cancer (n) & & \\
Unifocality & 64 & \\
Multifocality & 31 & \\
Location of cancer (n) & & \\
One lobe & 65 & \\
Both lobes & 30 & \\
Extrathyroidal invasion (n) & & \\
Absent & & \\
Present & & \\
Cervical lymph node metastasis (n) & & \\
Absent & 64 & \\
Present & & \\
Angiolymphatic invasion (n) & & \\
Absent & & \\
Present & & \\
\hline & & \\
\hline
\end{tabular}

PTC, papillary thyroid cancer; SD, standard deviation. PTC patients with inappropriate clinical data were excluded.

eral blood sample using the DNA isolation kit for blood (Roche, Indianapolis, IN, USA). SNP genotyping was conducted with direct sequencing using the following primers for each SNP: rs12731843 (sense, 5'-TTTCACTTTTGCTTAGCCTTCC-3'; antisense, 5'-AAGGTGATCCCAAATGTATGGA-3'), rs3753841 (sense, 5'-CAGCAGGTTTTGTCATGACTTT-3'; antisense, 5'-GGATTTTCCTGCATTTGCAATT-3'), rs1763347 (sense, 5'-CACCATGGAAAAATGTTTAAGC-3'; antisense, 5'-CCTTGAGGACCCTACAAAATGC-3') and rs2229783 (sense, 5'-CCTTTACCAATCTTGTCCTCCA-3'; antisense, 5'-TAGAATGAATGAGCTGCCAATG-3'). The PCR products were sequenced using an ABI PRISM 3730XL analyzer (PE Applied Biosystems, Foster City, CA, USA). Sequence data were analyzed using SeqManII software (DNAStar, Madison, WI, USA).

Statistical analysis. Continuous variables are presented as the means \pm SD and were analyzed by the independent t-test and Chi-square test using SPSS 18.0 software (SPSS, Inc., Chicago, IL, USA). For the analysis of the genetic data, SNPAnalyzer Pro (Istech, Goyang, Korea) and SNPStats (http://bioinfo.iconcologia.net/index.php) were used. The associations between genotypes of cSNPs and PTC, as well as any associations between cSNPs and the PTC subgroups, were estimated by computing the odds ratios (ORs) and their 95\% confidence 
Table II. Frequencies of the genotypes and alleles of COL11A1 polymorphisms in control subjects and patients with PTC.

\begin{tabular}{|c|c|c|c|c|c|c|}
\hline SNP & Model/allele & Type & $\begin{array}{c}\text { Control } \\
\mathrm{n}(\%)\end{array}$ & $\begin{array}{l}\text { PTC } \\
\text { n }(\%)\end{array}$ & OR $(95 \% \mathrm{CI})$ & $\mathrm{p}$-value \\
\hline \multirow{9}{*}{$\begin{array}{l}\text { rs } 12731843 \\
\text { Lys276Asn }\end{array}$} & \multirow[t]{3}{*}{ Codominant } & $\mathrm{A} / \mathrm{A}$ & $311(85.0)$ & $87 \quad(88.8)$ & Ref & \\
\hline & & $\mathrm{A} / \mathrm{C}$ & $52(14.2)$ & 11 (11.2) & $0.78(0.38-1.61)$ & 0.430 \\
\hline & & $\mathrm{C} / \mathrm{C}$ & $3(0.8)$ & $\begin{array}{ll}0 & (0.0)\end{array}$ & $0.00(0.00-\mathrm{NA})$ & \\
\hline & \multirow[t]{2}{*}{ Dominant } & AA & $311(85.0)$ & $87 \quad(88.8)$ & Ref & \\
\hline & & $\mathrm{AC} / \mathrm{CC}$ & $55(15.0)$ & 11 (11.2) & $0.71(0.35-1.46)$ & 0.340 \\
\hline & \multirow[t]{2}{*}{ Recessive } & $\mathrm{AA} / \mathrm{AC}$ & $363(99.0)$ & $98(100.0)$ & Ref & \\
\hline & & $\mathrm{CC}$ & $3(0.8)$ & $\begin{array}{ll}0 & (0.0)\end{array}$ & 0.00 (0.00-NA) & 0.130 \\
\hline & \multirow[t]{2}{*}{ Allele } & A & $674(92.1)$ & 185 (94.4) & Ref & \\
\hline & & $\mathrm{C}$ & $58 \quad(7.9)$ & $11 \quad(5.6)$ & $0.69(0.36-1.34)$ & 0.280 \\
\hline \multirow{9}{*}{$\begin{array}{l}\text { rs3753841 } \\
\text { Pro1335Leu }\end{array}$} & \multirow[t]{3}{*}{ Codominant } & $\mathrm{T} / \mathrm{T}$ & $158(43.2)$ & $53 \quad(54.1)$ & Ref & \\
\hline & & $\mathrm{T} / \mathrm{C}$ & $165(45.1)$ & $37 \quad(37.7)$ & $0.69(0.42-1.13)$ & 0.100 \\
\hline & & $\mathrm{C} / \mathrm{C}$ & 43 (11.7) & $8 \quad(8.2)$ & $0.45(0.19-1.04)$ & 0.160 \\
\hline & \multirow[t]{2}{*}{ Dominant } & $\mathrm{TT}$ & $158(43.2)$ & $53 \quad(54.1)$ & Ref & \\
\hline & & $\mathrm{TC} / \mathrm{CC}$ & $208(56.8)$ & $45 \quad(45.9)$ & $0.63(0.39-1.00)$ & 0.050 \\
\hline & \multirow[t]{2}{*}{ Recessive } & TT/TC & $323(88.2)$ & $90 \quad(91.8)$ & Ref & \\
\hline & & $\mathrm{CC}$ & 43 (11.8) & $8 \quad(8.2)$ & $0.53(0.23-1.20)$ & 0.110 \\
\hline & \multirow[t]{2}{*}{ Allele } & $\mathrm{T}$ & $481(65.7)$ & $143(73.0)$ & Ref & \\
\hline & & $\mathrm{C}$ & $251(34.3)$ & $53 \quad(27.0)$ & $0.71(0.50-1.01)$ & 0.060 \\
\hline \multirow{9}{*}{$\begin{array}{l}\text { rs1763347 } \\
\text { Gly1516Gly }\end{array}$} & \multirow[t]{3}{*}{ Codominant } & $\mathrm{C} / \mathrm{C}$ & $175(47.8)$ & $61 \quad(62.2)$ & Ref & \\
\hline & & $\mathrm{C} / \mathrm{T}$ & $160(43.7)$ & $33 \quad(33.7)$ & $0.52(0.32-0.86)$ & 0.030 \\
\hline & & $\mathrm{T} / \mathrm{T}$ & $31 \quad(8.5)$ & $4 \quad(4.1)$ & $0.38(0.12-1.14)$ & 0.070 \\
\hline & \multirow[t]{2}{*}{ Dominant } & $\mathrm{CC}$ & $175(47.8)$ & $61 \quad(62.2)$ & Ref & \\
\hline & & $\mathrm{CT} / \mathrm{TT}$ & $191(52.2)$ & $37 \quad(37.8)$ & $0.50(0.31-0.81)$ & 0.0042 \\
\hline & \multirow[t]{2}{*}{ Recessive } & $\mathrm{CC} / \mathrm{CT}$ & $335(91.5)$ & $94 \quad(95.9)$ & Ref & \\
\hline & & $\mathrm{TT}$ & $31 \quad(8.5)$ & $4 \quad(4.1)$ & $0.49(0.17-1.47)$ & 0.170 \\
\hline & \multirow[t]{2}{*}{ Allele } & $\mathrm{C}$ & $510(69.7)$ & 155 (79.1) & Ref & \\
\hline & & $\mathrm{T}$ & $222(30.3)$ & 41 (20.9) & $0.61(0.42-0.89)$ & 0.010 \\
\hline rs2229783 & \multirow[t]{3}{*}{ Codominant } & $\mathrm{CC}$ & $139(38.0)$ & $50 \quad(51.0)$ & Ref & \\
\hline \multirow[t]{8}{*}{ Ile1602Ile } & & $\mathrm{CT}$ & $172(47.0)$ & $41 \quad(41.8)$ & $0.65(0.39-1.06)$ & 0.090 \\
\hline & & TT & $55(15.0)$ & $7 \quad(7.2)$ & $0.30(0.13-0.73)$ & 0.017 \\
\hline & \multirow[t]{2}{*}{ Dominant } & $\mathrm{CC}$ & $139(38.0)$ & $50 \quad(51.0)$ & Ref & \\
\hline & & $\mathrm{CT} / \mathrm{TT}$ & $227(62.0)$ & $48 \quad(49.0)$ & $0.55(0.35-0.89)$ & 0.014 \\
\hline & \multirow[t]{2}{*}{ Recessive } & $\mathrm{CC} / \mathrm{CT}$ & $311(85.0)$ & $91 \quad(92.9)$ & Ref & \\
\hline & & $\mathrm{TT}$ & $55(15.0)$ & $7 \quad(7.1)$ & $0.38(0.16-0.87)$ & 0.013 \\
\hline & \multirow[t]{2}{*}{ Allele } & $\mathrm{C}$ & $450(61.5)$ & 141 (71.9) & Ref & \\
\hline & & $\mathrm{T}$ & $282(38.5)$ & 55 (28.1) & $0.62(0.44-0.88)$ & 0.007 \\
\hline
\end{tabular}

PTC, papillary thyroid cancer; SNP, singe nucleotide polymorphism; OR, odds ratio; CI, confidence interval; NA, not applicable; Ref, reference. Bold print represents statistically significant values $(\mathrm{p}<0.05 / 4)$.

intervals (CIs) with logistic regression analyses, controlling for age and gender as covariables. In logistic regression analysis for each cSNP, models assuming either codominant inheritance (that is, the relative hazard differed between subjects with one minor allele and those with two minor alleles), dominant inheritance (that is, subjects with one or two minor alleles had the same relative hazard for the disease), or recessive inheritance (that is, only subjects with two minor alleles were at increased risk of the disease) were used. Linkage disequilibrium (LD) was tested using Haploview version 4.2 (Broad Institute, Cambridge, MA, USA). The LD block was constructed using Gabriel's method (24). The association of SNPs and haplotypes was analyzed using HapAnalyzer version 1.0 (http://hap.ngri.go.kr/). To avoid chance findings due to multiple testing, the Bonferroni correction was applied by lowering the significance levels to $\mathrm{p}=0.013(\mathrm{p}=0.05 / 4)$ for the four SNPs.

\section{Results}

Four cSNPs of the COL11A1 gene were polymorphic, and the genotype distributions of the cSNPs were in Hardy-Weinberg 
Table III. Haplotype analysis of COL11 A1 gene polymorphisms in PTC patients and control subjects.

\begin{tabular}{|c|c|c|c|c|c|c|c|c|c|c|}
\hline \multirow[t]{2}{*}{ Haplotype } & \multirow[t]{2}{*}{ Type } & \multicolumn{3}{|c|}{ Control } & \multicolumn{3}{|c|}{ PTC } & \multirow[t]{2}{*}{ Model } & \multirow[t]{2}{*}{ OR (95\% CI) } & \multirow[t]{2}{*}{$\mathrm{p}$-value } \\
\hline & & Freq & $\mathrm{n}$ & $\%$ & Freq & $\mathrm{n}$ & $\%$ & & & \\
\hline \multirow[t]{3}{*}{$\mathrm{CC}$} & $\mathrm{H} / \mathrm{H}$ & 0.61 & 139 & 38.0 & 0.71 & 50 & 51.0 & Codominant & $1.56(1.11-2.21)$ & 0.011 \\
\hline & $\mathrm{H} /-$ & & 172 & 47.0 & & 40 & 40.8 & Dominant & $1.99(0.91-4.33)$ & 0.080 \\
\hline & $-/-$ & & 55 & 15.0 & & 8 & 8.2 & Recessive & $1.70(1.09-2.66)$ & 0.020 \\
\hline \multirow[t]{3}{*}{ TT } & $\mathrm{H} / \mathrm{H}$ & 0.30 & 31 & 8.5 & 0.20 & 3 & 3.1 & Codominant & $0.58(0.39-0.85)$ & 0.006 \\
\hline & $\mathrm{H} /-$ & & 160 & 43.7 & & 34 & 34.7 & Dominant & $0.56(0.35-0.88)$ & 0.080 \\
\hline & $-/-$ & & 175 & 47.8 & & 61 & 62.2 & Recessive & $0.34(0.10-1.14)$ & 0.600 \\
\hline \multirow[t]{3}{*}{ CT } & $\mathrm{H} / \mathrm{H}$ & 0.08 & 3 & 0.8 & 0.08 & 0 & 0.0 & Codominant & $0.93(0.51-1.67)$ & 0.800 \\
\hline & $\mathrm{H} /-$ & & 54 & 17.8 & & 15 & 15.3 & Dominant & $0.98(0.53-1.82)$ & 0.950 \\
\hline & $-/-$ & & 309 & 84.4 & & 83 & 84.7 & Recessive & $0.00(0.00-\mathrm{NA})$ & 1.000 \\
\hline
\end{tabular}

Freq, frequency; PTC, papillary thyroid cancer. Haplotype is comprised of rs1763347 and rs2229783. Bold print represents statistically significant values $(\mathrm{p}<0.05)$.

equilibrium in the control group ( $\mathrm{p}>0.05$; data not shown). The power of the sample size was calculated to verify the data using a genetic power calculator (http://pngu.mgh.harvard. $\mathrm{edu} / \sim \mathrm{purcell} / \mathrm{gpc} / \mathrm{cc} 2 . \mathrm{html})$. In the present study, the sample powers of the SNPs were 0.872 (rs12731843, number of effective sample for $80 \%$ power $=81), 0.863($ rs 3753841 , number of effective sample for $80 \%$ power $=83$ ), 0.868 (rs1763347, number of effective sample for $80 \%$ power $=82$ ) and 0.862 (rs4753426, number of effective sample for $80 \%$ power $=83$ ), respectively ( $\alpha=0.05$, genotype relative risk 2 -fold). We therefore have statistical confidence in our results.

As shown in Table II, rs1763347 and rs2229783 of the COL11A1 gene showed a significant association with PTC. Association of rs 1763347 with PTC was detected in the dominant model (CT/TT vs. CC; $p=0.0042, \mathrm{OR}=0.50,95 \% \mathrm{CI}$ 0.31-0.81). Frequencies of the genotype containing the $\mathrm{T}$ allele (CT and TT genotypes) were lower in the PTC patients (37.8\%) compared to the control subjects (52.2\%). Allele frequency analysis also revealed an association between the $\mathrm{T}$ allele and a reduced risk of PTC ( $\mathrm{p}=0.010, \mathrm{OR}=0.61,95 \%$ CI $0.42-0.89$ ). Frequencies of the $\mathrm{C}$ and $\mathrm{T}$ alleles were 69.7 and $30.3 \%$ in the control subjects, and 79.1 and $20.9 \%$ in the PTC patients, respectively. This result indicated that the $\mathrm{T}$ allele was associated with a reduced risk of PTC. As well, rs2229783 was associated with PTC in the codominant (TT vs. CC; $\mathrm{p}=0.017$, $\mathrm{OR}=0.30,95 \%$ CI $0.13-0.73)$, dominant $(\mathrm{p}=0.014, \mathrm{OR}=0.55$, 95\% CI 0.35-0.89) and recessive models $(\mathrm{p}=0.013, \mathrm{OR}=0.38$, 95\% CI 0.16-0.87). However, the significance of the association did not remain after Bonferroni correction. In the allele analysis, a significant association was demonstrated $(\mathrm{p}=0.007$, $\mathrm{OR}=0.62,95 \% \mathrm{CI} 0.44-0.88$ ). The frequency of the $\mathrm{T}$ allele was lower in the PTC patients (28.1\%) than in the control subjects (38.5\%). This result indicated that the $\mathrm{T}$ allele contributed to a decreased risk of PTC. No association of rs12731843 and rs3753841 with PTC was detected.

We performed a further analysis according to the clinical symptoms of PTC, including the size of the cancers $(<1$ and $\geq 1 \mathrm{~cm}$ ), the number of cancers (unifocality and multifocality), location of the cancers (one lobe and both lobes), invasion (+/-)

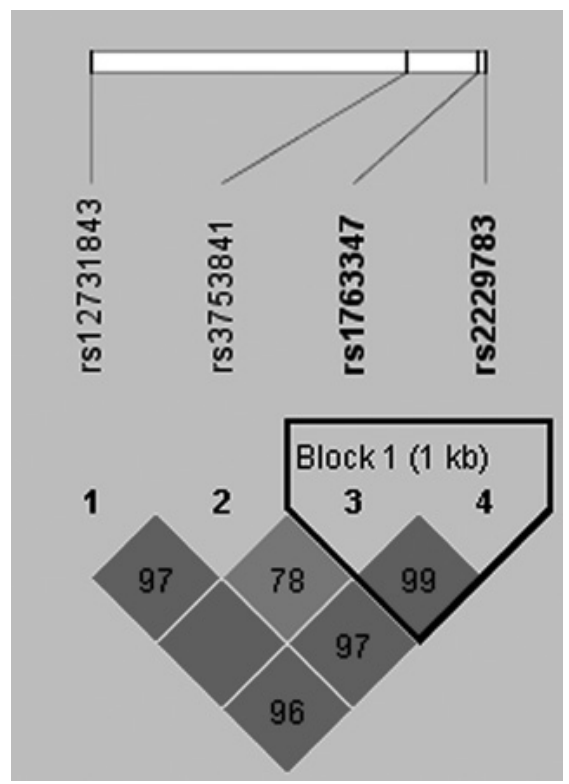

Figure 1. Linkage disequilibrium (LD) in the collagen type XI $\alpha 1$ (COL11A1) gene. Pairwise LD between SNPs of COL11A1 was measured by LD coefficiency (D') in 366 controls. LD block consists of rs1763347 and rs2229783.

and lymph node metastasis (+/-). In the analysis according to cancer size of PTC, a weak association of rs1763347 was revealed with PTC patients with cancer size of $\geq 1 \mathrm{~cm}$ in the codominant (CT vs. CC; $\mathrm{p}=0.044, \mathrm{OR}=0.39,95 \%$ CI $0.16-0.97$ ) and dominant models (CT/TT vs. CC; $\mathrm{p}=0.046, \mathrm{OR}=0.42$, 95\% CI 0.18-1.00). In the codominant model, the frequencies of the CC, CT and TT genotypes were 53.1, 42.9 and $4.1 \%$, respectively, in the PTC patients with cancer size of $<1 \mathrm{~cm}$, and 72.3, 23.4 and 4.3\%, respectively, in the PTC patients with cancer size of $\geq 1 \mathrm{~cm}$ (data not shown). However, this significance did not remain after the Bonferroni correction.

In the analysis according to other symptoms, we were not able to find any association with polymorphisms of COL11A1 (data not shown). 
Four SNPs of the COL11A1 gene were analyzed for LD and haplotypes using Haploview 4.2. As shown in Fig. 1, LD block was constructed between rs1763347 and rs2229783 (D' $\geq 0.95$, $r^{2} \geq 0.8$ ). Thus, we analyzed the association of haplotypes consisting of rs1763347 and rs2229783 with PTC. Haplotype analysis revealed that the $\mathrm{CC}$ haplotype was associated with PTC in the codominant $(\mathrm{p}=0.011, \mathrm{OR}=1.56,95 \%$ CI 1.11-2.21) and recessive models $(\mathrm{p}=0.020, \mathrm{OR}=1.70,95 \%$ CI $1.09-2.66)$ (Table III). The TT haplotype was also associated with PTC in the codominant model $(\mathrm{p}=0.006, \mathrm{OR}=0.58,95 \% \mathrm{CI} 0.39-0.85)$. The frequency of the CC haplotype was higher in the PTC patients $(0.71)$ compared to the control subjects $(0.61)$, whereas that of the TT haplotype was lower $(0.20$ in PTC patients and 0.30 in control subjects). This result indicated that the $\mathrm{CC}$ and TT haplotypes may be related to the risk of PTC.

\section{Discussion}

The results of the present study revealed an association between the COL11A1 gene and PTC in a Korean population. The rs1763347 and rs2229783 polymorphisms of the COL11A1 gene were associated with PTC, but not rs12731843 and rs3753841. In particular, the T allele of rs1763347 and rs2229783 was associated with a decreased risk of PTC. Moreover, the CC and TT haplotypes consisting of rs1763347 and rs2229783 were related to PTC.

Notably, in previous studies, overexpression of the COL11A1 gene was demonstrated in various types of cancers, such as NSCLC, ovarian, oral cavity and colorectal cancers. COL11A1 was proposed as a marker for NSCLC $(13,14)$. Additionally, Chong et al (14) found that overexpression of COL11A1 was correlated with pathological stage, lymph node metastasis and poor prognosis of NSCLC. Moreover, overexpression of the COL11A1 gene was correlated with invasion and metastasis of ovarian, oral cavity and colorectal cancers $(15,16)$. Considering its overexpression in various types of cancers and, moreover, the contribution of collagen in the formation of PBs in PTC (5-7), we postulate that the COL11A1 level may be increased in PTC similar to other cancers.

In a previous study, the $\mathrm{T}$ allele of $\mathrm{rs} 1676486(\mathrm{C} / \mathrm{T})$ of the COL11A1 gene exhibited a significant association with an increased risk of lumbar disc herniation (LDH) in a Japanese population (25). In addition, the mRNA expression level of COL11A1, which was decreased according to the severity of degeneration in patients with $\mathrm{LDH}$, was lower in the intervertebral discs of patients with minor allele $\mathrm{T}$ allele than with major allele $\mathrm{C}$ allele (25). These authors also showed that the decrease in the expression of the $\mathrm{T}$ allele resulted from transcription degradation induced in the $\mathrm{T}$ allele (25). The rs1676486 with rs1763347 was in strong $L D\left(r^{2} \geq 0.8\right)$ in the HapMap database for Chinese and Japanese population (http://www.hapmap.org/; genome build 36). Thus, rs1763347 as well as rs1676486 may also influence the expression of the COL11A1 gene, and minor allele T alleles of rs1763347 may decrease the level of COL11A1. Moreover, rs1763347 and rs2229783 were in strong LD block in our study $\left(r^{2} \geq 0.8\right)$. Thus, $\mathrm{T}$ alleles of both rs1763347 and rs2229783 may cause a decrease in COL11A1 expression.

In our data, T alleles of rs1763347 and rs2229783 were associated with a reduced risk of PTC. The CC and TT haplotypes comprised of these SNPs also showed a significant association with PTC with decreased frequency of the TT haplotype in PTC patients. Additionally, rs1763347 was associated with cancer size, and $\mathrm{T}$ allele frequencies of rs1763347 were lower in PTC patients with a cancer size of $\geq 1 \mathrm{~cm}$ than in those with a cancer size of $<1 \mathrm{~cm}$, although the significance did not remain after Bonferroni correction. While to our knowledge there has not been any report concerning the expression of COL11A1 in PTC, we speculate that the T alleles of both rs1763347 and rs2229783 may induce a relative decrease in COL11A1 expression in PTC compared to the $\mathrm{C}$ allele, and this decrease may be associated with a reduced risk of PTC. Further study is required to assess whether the expression of COL11A1 is up-regulated in PTC, and whether the expression level is related to alleles of rs1763347 and rs2229783 of the COL11A1 gene. In addition, due to the relatively small number of subjects, our findings are considered preliminary and need to be validated in further studies using larger sample sizes of these subpopulations.

In conclusion, rs1763347 and rs2229783 polymorphisms of the COL11A1 gene are significantly associated with PTC. In particular, the T alleles of rs2229783 and rs1763347 may be implicated as a protective factor against PTC. These findings provide evidence that the COL11A1 gene may play a role in the pathophysiology of PTC.

\section{Acknowledgements}

This study was supported by a grant from the Kyung Hee University in 2011 (KHU-20110061).

\section{References}

1. Hundahl SA, Fleming ID, Fremgen AM and Menck HR: A National Cancer Data Base report on 53,856 cases of thyroid carcinoma treated in the U.S., 1985-1995. Cancer 83: 2638-2648, 1998.

2. Dohán O, Baloch Z, Bánrévi Z, Livolsi V and Carrasco N: Rapid communication: predominant intracellular overexpression of the $\mathrm{Na}^{+} / \mathrm{I}^{-}$symporter (NIS) in a large sampling of thyroid cancer cases. J Clin Endocrinol Metab 86: 2697-2700, 2001.

3. Carcangiu MI, Zampi G, Pupi A, Castognoli A and Rosai J: Papillary carcinoma of the thyroid: a clinicopathologic study of 241 cases treated at the University of Florence, Italy. Cancer 55: 805-828, 1985.

4. Johannessen JV and Sobrinho-Simões M: The origin and significance of thyroid psammoma bodies. Lab Invest 43: 287-296, 1980.

5. Endo T, Ohta K and Kobayashi T: Expression and function of Cbfa-1/Runx2 in thyroid papillary carcinoma cells. J Clin Endocrinol Metab 93: 2409-2412, 2008.

6. Kiyozuka Y, Nakagawa H, Senzaki H, et al: Bone morphogenetic protein-2 and type IV collagen expression in psammoma bodyforming ovarian cancer. Anticancer Res 21: 1723-1730, 2001.

7. Tsuchida T, Matsumoto M, Schirayama Y, Kasai H and Kawamoto K: Observation of psammoma bodies in cultural meningiomas: analysis of three-dimensional structure using scanning and transmission electron microscopy. Ultrastruct Pathol 20: 241-247, 1996.

8. Morris NP and Bächinger HP: Type XI collagen is a heterotrimer with the composition $(1 \alpha, 2 \alpha, 3 \alpha)$ retaining non-triple-helical domains. J Biol Chem 262: 11345-11350, 1987.

9. So CL, Kaluarachchi K, Tam PP and Cheah KS: Impact of mutations of cartilage matrix genes on matrix structure, gene activity and chondrogenesis. Osteoarthritis Cartilage 9: S160-S173, 2001.

10. Yoshioka H, Greenwel P, Inoguchi K, et al: Structural and functional analysis of the promoter of the human $\alpha 1$ (XI) collagen gene. J Biol Chem 270: 418-424, 1995. 
11. Li Y, Lacerda DA, Warman ML, et al: A fibrillar collagen gene, Col11a1, is essential for skeletal morphogenesis. Cell 80: 423-430, 1995

12. Seegmiller R, Fraser FC and Sheldon H: A new chondrodystrophic mutant in mice. Electron microscopy of normal and abnormal chondrogenesis. J Cell Biol 48: 580-593, 1971.

13. Wang KK, Liu N, Radulovich N, et al: Novel candidate tumor marker genes for lung adenocarcinoma. Oncogene 21: 7598-7604, 2002.

14. Chong IW, Chang MY, Chang HC, et al: Great potential of a panel of multiple hMTH1, SPD, ITGA11 and COL11A1 markers for diagnosis of patients with non-small cell lung cancer. Oncol Rep 16: 981-988, 2006.

15. Kim H, Watkinson J, Varadan V and Anastassiou D: Multi-cancer computational analysis reveals invasion-associated variant of desmoplastic reaction involving INHBA, THBS2 and COL11A1. BMC Med Genomics 3: 51, 2010.

16. Schmalbach CE, Chepeha DB, Giordano TJ, et al: Molecular profiling and the identification of genes associated with metastatic oral cavity/pharynx squamous cell carcinoma. Arch Otolaryngol Head Neck Surg 130: 295-302, 2004.

17. Chattopadhyay I, Singh A, Phukan R, et al: Genome-wide analysis of chromosomal alterations in patients with esophageal squamous cell carcinoma exposed to tobacco and betel quid from high-risk area in India. Mutat Res 696: 130-138, 2010.

18. Kondo T, Ezzat S and Asa SL: Pathogenetic mechanisms in thyroid follicular-cell neoplasia. Nat Rev Cancer 6: 292-306, 2006.
19. Zatelli MC, Trasforini G, Leoni S, et al: BRAF V600E mutation analysis increases diagnostic accuracy for papillary thyroid carcinoma in fine-needle aspiration biopsies. Eur J Endocrinol 161: 467-473, 2009.

20. Gudmundsson J, Sulem P, Gudbjartsson DF, et al: Common variants on $9 \mathrm{q} 22.33$ and $14 \mathrm{q} 13.3$ predispose to thyroid cancer in European populations. Nat Genet 41: 460-464, 2009.

21. Baida A, Akdi M, González-Flores E, Galofré P, Marcos R and Velázquez A: Strong association of chromosome 1p12 loci with thyroid cancer susceptibility. Cancer Epidemiol Biomarkers Prev 17: 1499-1504, 2008.

22. Jazdzewski K, Murray EL, Franssila K, Jarzab B, Schoenberg DR and de la Chapelle A: Common SNP in pre-miR-146a decreases mature miR expression and predisposes to papillary thyroid carcinoma. Proc Natl Acad Sci USA 105: 7269-7274, 2008.

23. He H, Nagy R, Liyanarachchi S, et al: A susceptibility locus for papillary thyroid carcinoma on chromosome 8q24. Cancer Res 69: 625-631, 2009.

24. Gabriel SB, Schaffner SF, Nguyen H, et al: The structure of haplotype blocks in the human genome. Science 296: 2225-2229, 2002.

25. Mio F, Chiba K, Hirose Y, et al: A functional polymorphism in COL11A1, which encodes the $\alpha 1$ chain of type XI collagen, is associated with susceptibility to lumbar disc herniation. Am J Hum Genet 81: 1271-1277, 2007. 